\title{
Influence of Calcination on Mineralogical and Strength Properties of Self Activated Green Material (SAGreM)
}

\author{
Ahmad Ruslan Mohd Ridzuan ${ }^{1 *}$, Muhd Norhasri Muhd Sidek ${ }^{1}$, Khairulniza \\ Ahmad Anuar ${ }^{1}$
}

${ }^{1}$ Institute for Infrastructure Engineering and Sustainable Management, Faculty of Civil Engineering, Universiti Teknologi MARA, Shah Alam, Selangor, 40450, MALAYSIA

*Corresponding Author

DOI: https://doi.org/10.30880/ijscet.2019.10.01.005

Received 13 January 2019; Accepted 23 May 2019; Available online 01 June 2019

\begin{abstract}
Concrete is an alkaline activated material consist of lime which contribute from limestone. This SAGreM has potential to be supplementary cementitious material because of the oxide content most similar with cement. SAGreM is a new sources generated from recycling of industrial waste which has similar affect to limestone. The purposed of this study is to investigate the mineralogical composition, particle size distribution and strength development of difference calcination temperature of SAGreM and the effect after activation with water. The mineralogical properties were investigated using by $\mathrm{x}$-ray fluorescence and $\mathrm{x}$-ray diffraction. The mineralogical test results showed that the SAGreM consists of calcite, free lime, and probably a crystal phase. SAGreM creates very well reactivity with water and gain the strength $4.85 \mathrm{MPa}$ at 28 days in ambient condition exposure.
\end{abstract}

Keywords: Self Activated Green Material, compressive strength, particle size distribution, X-Ray Diffraction, Xray fluorescence, FESEM, Energy Dispersive X-ray

\section{Introduction}

The paper industry in Malaysia is sustainable growth with as much contributed as $40 \%$ of total rubbish in the country (Ridzuan et al., 2014). The massive growth of sludge maintains to be produced as by products. In paper recycling process, several types of waste sludge are produced. This sludge contains organics as well as inorganic fillers of the recycled paper such as kaolin clay, calcium carbonate, talc, and titanium dioxide. Significantly of the waste is reused in cement and ceramics industries and also for soil improvement (Journal, Centre \& Uk, 2015). The inorganic matter comes from the de-inking and whitening processes. Under a controlled calcination, the clay materials in the paper sludge, mainly kaolinite, can be transformed into active metakaolinite. Once thermally activated (in the range of $650-700^{\circ} \mathrm{C}$ ), paper sludge turns out to be an alternative source of recycled metakaolin. This product is characterized by its high pozzolanic activity and improved performance with regard to the benefits of certain binary cements (Gracia Gimenez et al., 2015).

A detailed study on the influence of calcining conditions such as temperature and time on the mineralogy and texture of calcined products was carried out by Seok Jang et al., 2018. The sludge composition, constitutes mainly calcite and kaolinite with a high degree of purity, permits its possible reuse as a pozzolanic material. The results indicate that optimal calcination conditions in accordance to the presence of organic matter and pozzolanic activity 
have occurred at temperature of $700{ }^{\circ} \mathrm{C}$ within duration of $2 \mathrm{~h}$. Lime combination similar to that showed by natural metakaolinite is observed. Under this condition $\left(700^{\circ} \mathrm{C} / 2 \mathrm{~h}\right)$, cellulose fibres do not appear at all. At greater temperatures, the formation of new mineral phases of calcium silicates reduces the pozzolanic activity. On the other hand, the surface reactivates decrease as a consequence of the crystalline phase production (Seok Jang et al., 2018).

On the other hand, a large fraction of the sludge is still incinerated which serves to recover energy and particularly to reduce the volume of waste material to be handled. The ashes generated in this process often referred to as wastepaper sludge ash (WPSA) which differs widely in their chemical and mineralogical composition. It depends on the composition of the feedstock, the production, waste treatment processes and the conditions of combustion (Journal, Centre \& Uk, 2015). Despite the volume reduction by incineration, the amount of waste, such as WPSA is still very large, which poses a significant problem to the paper industries, if it is still no added value in application of WPSA as Self Activated Green Material (SAGreM).

In this context, several studies had investigated the use of SAGreM as cementitious material, either alone, in blends with Portland cement or mixed with other binder materials (Bai et al., 2003; Mozaffari et al., 2009; Corinaldesi, Fava, \& Ruello, 2011; Segui et al., 2012; Segui et al., 2013; Yan \& Sagoe-Crentsil, 2016; Kinuthia, 2016). These studies confirmed that SAGreM generally possesses good cementitious properties. Thus, in principle it may be used as binder or as supplementary cementitious material, which would not only reduce the amount of waste from paper industry to be landfilled, but would also contribute to lowered carbon dioxide emissions by replacement of Portland cement in the construction industries.

Ahmadi and Al-Khaja (2001) have conducted a series of examinations on the use of incinerated paper sludge ash as building and construction material. They suggested that a maximum of $5 \%$ of paper sludge by mass of the binder may be used as an additive in concrete. Thus, studies are conducted to convert paper sludge into various materials such as highly reactive meta-kaolin, zeolites, coating pigment and papermaking fillers, polymer composites, glass-ceramics, etc.(Bai et al., 2003; Hanzic \& Ho., 2017).

However, only few studies had provided information about which compounds formed on hydration of SAGreM or blends containing SAGreM (Mozaffari et al., 2009; Segui et al., 2013). Since the phase assemblage of the hardened pastes determines their mechanical properties and durability, it is essential to provide more data on the evolution of the reaction products. It may include the influence of specific compounds, which introduced intentionally and contained in the cementitious materials which used for mixing with the SAGreM. The present work aims to contribute to these issues by analyzing the SAGreM in term of strength development and reaction products after addition of water.

\section{Experimental Program}

\subsection{Material Composition}

The Self Activated Green Material (SAGreM) precursor used in this investigation is Waste Paper Sludge Ash (WPSA) obtained from Malaysian Newsprint Industries, Mentakab Pahang, Malaysia. The raw SAGreM specific gravity is $1.9 \mathrm{~g} / \mathrm{cm} 3$ and the fineness (passing $90 \mu \mathrm{m}$ sieves) is $91.1 \%$. The oxide compositions of the precursors are shown in Table 1. It is notable that the raw SAGreM used is very high in $\mathrm{CaO}$ with percentage of $52 \%, \mathrm{SiO}_{2}$ is $13 \%$ and $\mathrm{Al}_{2} \mathrm{O}_{3}$ is $8 \%$. Compared to calcined SAGreM at 500 , the $\mathrm{CaO}$ contain is $51.7 \%$, very small differ from the raw sample, $\mathrm{SiO}_{2}$ is $13 \%$ and $\mathrm{Al}_{2} \mathrm{O}_{3}$ is $8 \%$ similar with raw SAGreM. Calcined SAGreM at 700 oC also shows very small differ from raw and 500oC calcination. However, when the raw SAGreM mix mix water the CaO contain change to $47 \%, \mathrm{SiO}_{2}$ is $11 \%$ and $\mathrm{Al}_{2} \mathrm{O}_{3}$ is $7 \%$. But all the samples contain very high LOI value.

The Limiting Oxygen Index (LOI) test (described for example in ASTM D2863) is probably the most widely used method for assessing flammability [14]. In this test the minimum oxygen fraction in an oxygen/nitrogen mixture that will enable a slowly rising sample of the gas mixture to support combustion of a candle-like sample under specified test conditions is measured. The top edge of the test sample is ignited, and the oxygen concentration in the flow is decreased until the flame is no longer supported.

The reasons for the differences between the polymers are various, but in particular two factors may be noted, the higher the hydrogen to carbon ratio in the polymer, the greater is the tendency to burning (other factors being equal) and some polymers on burning emit blanketing gases that suppress burning. While the limiting oxygen index (LOI) test is quite fundamental, it does not characterize the burning behavior of the polymer. 
Table 1 - Oxide composition of SAGreM

\begin{tabular}{ccccc}
\hline $\begin{array}{c}\text { Formula \% } \\
\text { / Material }\end{array}$ & $\begin{array}{c}\text { SAGreM } \\
\text { Raw }\end{array}$ & $\begin{array}{c}\text { SAGreM } \\
\text { Raw }+ \\
\text { Water }\end{array}$ & $\begin{array}{c}\text { SAGreM } \\
\mathbf{5 0 0}\end{array}$ & $\begin{array}{c}\text { SAGreM } \\
\mathbf{7 0 0}\end{array}$ \\
\hline Na2O & 0.203 & 0.268 & 0.195 & 0.206 \\
MgO & 1.922 & 1.351 & 1.843 & 1.829 \\
Al2O3 & 8.358 & 7.563 & 8.111 & 8.416 \\
SiO2 & 13.465 & 11.374 & 13.153 & 13.472 \\
CaO & 52.032 & 47.356 & 51.796 & 51.044 \\
LOI & 22.45 & 47.71 & 22.85 & 22.73 \\
\hline
\end{tabular}

All samples were formulated with a water/binder ratio between 0.40 . It was cured in sealed at curing environment under which the material would harden sufficiently rapidly. But it is not far removed from the ambient conditions prevailing in many parts of the world, and it is relevant for practical purposes.

\subsection{Analytical Techniques}

\subsubsection{Particle Size Analyzer}

Partical size analysis was performed on raw material using ZETA Potential meter with particle seizer instrument. Zeta potential is a measure of the charge on a particle surface in a specific liquid medium. This value of surface charge is useful for understanding and predicting interactions between particles in suspension. Zeta potential is defined as the potential measured in $\mathrm{mV}$ at the slipping plane distance from the particle surface.

Microstructural and chemical analyses were performed on paste samples after 28 days of curing. The X-ray diffraction (XRD) using an X'Pert PRO PAN analytical instrument which scanning from 5o to 90 o $2^{\theta}$, with a 0.02 step size and 2 s/step count time. The voltage used $45 \mathrm{KV}$ with 40 MA current.

Field Emission scanning electron microscopy (FESEM) with energy dispersive X-ray (EDX) was analyzed, at an accelerating voltage of $15 \mathrm{kV}$ using a Carl Zeiss SMT Supra 40VP instrument. Paste samples of SAGreM were sectioned, and polished up to $\mathrm{lm}$ surface fineness using diamond paste. Data points, and mapping method were collected for the morphological and elemental analysis of each sample.

\section{Results and Discussion}

\subsection{Particle Size of Raw Materials}

The particle size and particle size distribution (PSD) of these materials provide importance information to the end user because they affect mechanical properties such as strength, surface area and density. The average particle size distribution of raw SAGreM is 3357 (d. $\mu \mathrm{m})$. However, the particles detected shows a presence of sedimenting particles, the sample was fluorescence and absorbance (coloured samples). While, the average particle size distribution of calcined SAGreM at $500^{\circ} \mathrm{C}$ is $4005(\mathrm{~d} . \mu \mathrm{m})$ and at $700 \mathrm{oC}$ is $3388(\mathrm{~d} . \mu \mathrm{m})$. The temperatures affect the particle size and the homogeneity. Figure 1 shows the result, sample of calcined SAGreM at 500oC contain homogeneous and the most fineness particle size compared to other. The percentage of effective size for raw SAGreM is $15 \%, \mathrm{SAGreM}_{500}$ is $35 \%$ and SAGreM $\mathrm{M}_{700}$ is $25 \%$. Based on these results, SAGreM $\mathrm{S}_{500}$ where been used in paste production. However, based from all sample of SAGreM the particle size distribution still in range 1000 to 5000 d. $\mathrm{mm}$ and it consider as micro filler. Fillers can partially replace cement and at the same time improve the properties and the microstructure of the concrete [13]. 




Fig. 1 - particle size distribution for SAGreM, Calcined SAGreM at $500^{\circ} \mathrm{C}$ and $700^{\circ} \mathrm{C}$

\subsection{X-Ray Diffraction of Raw Materials and Alkali-Activated Binders}

The X-ray diffractograms of SAGreM are shown in Figure 2, Figure 3, and Figure 4. The raw SAGreM shows in Figure 2, as main crystalline phases were calcite $\left(\mathrm{CaCO}_{3}\right) 78 \%$ with high position at $29.412^{\theta}$, and lime $(\mathrm{CaO}) 56 \%$ with high position at $37.382^{\theta}$. However, influence of temperature shows the calcite were transformed calcite into calcium oxide as shown in Figure 3 and Figure 4. The SAGreM calcined at $500^{\circ} \mathrm{C}$ shows in Figure 3 and SAGreM calcined at $700^{\circ} \mathrm{C}$ shows in Figure 4, as main crystalline phases were burn lime (Ca) with same high peak position at $37.362^{\theta}$. The value of counts for raw SAGreM, SAGreM $\mathrm{S}_{500}$ and $\mathrm{SAGreM}_{700}$ is 5000 of $\mathrm{CaCO}_{3}, 6000$ of $\mathrm{CaO}$, and 5500 of $\mathrm{CaO}$ respectively. SAGreM $\mathrm{M}_{500}$ where been used in paste production because of high volume and homogeneous formation. The reaction of heat shows the single element of calcite can be transform into calcium oxide. This shows that heat chemically react with the SAGreM and changed into $\mathrm{SAGreM}_{500}$ and $\mathrm{SAGreM}_{700}$.

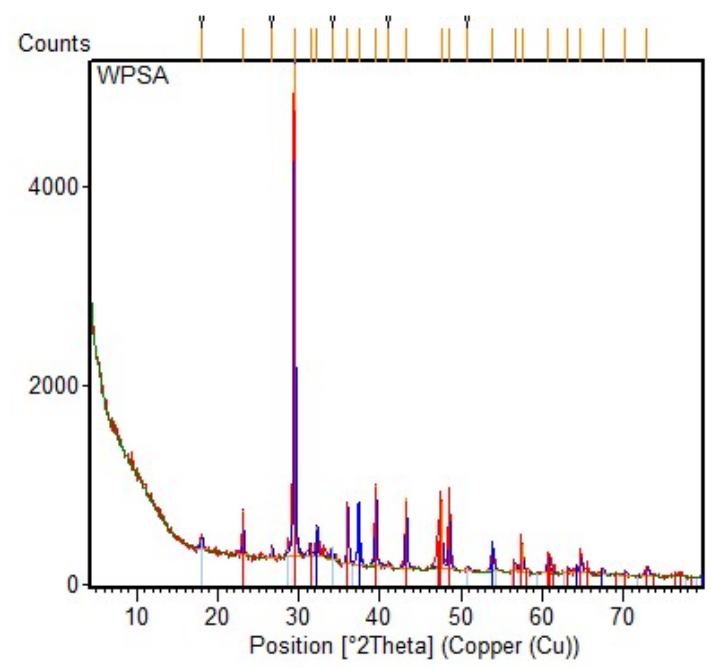

Fig. 2 - XRD of SAGreM 


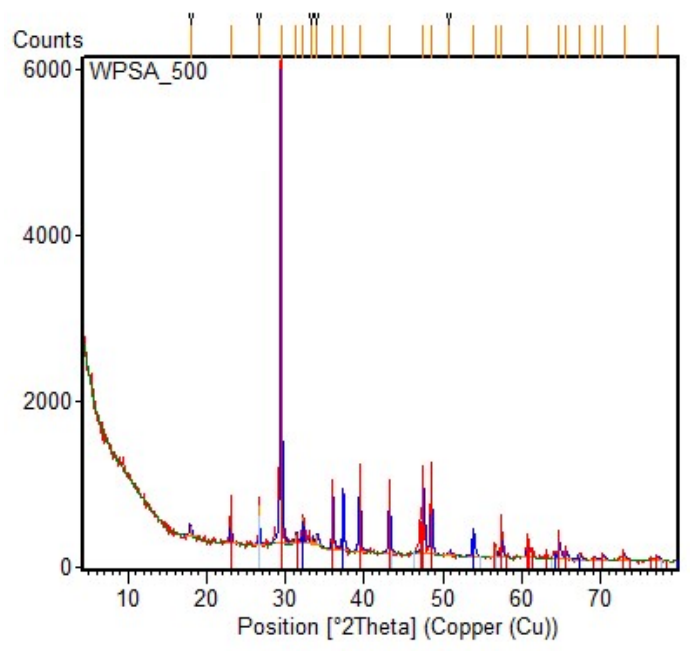

Fig. 3 - XRD of calcined SAGreM at $500^{\circ} \mathrm{C}$

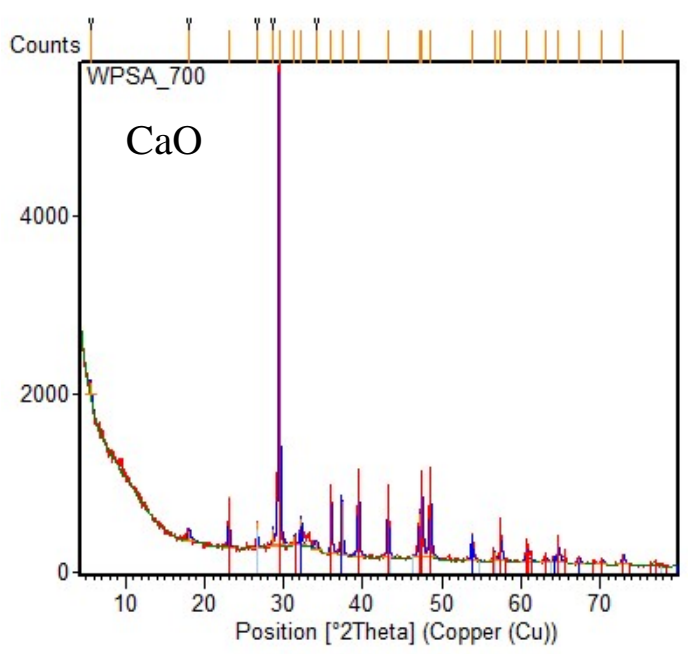

Fig. 4 - XRD of calcined SAGreM at $700^{\circ} \mathrm{C}$

Quicklime (CaO), is produced from limestone $\left(\mathrm{CaCO}_{3}\right)$ by calcining (burning) at high temperatures to decompose the limestone to quicklime. Because of this calcination, the product is sometimes called burnt lime or the name is abbreviated to lime. The process of the progressive change of limestone to lime is called endothermic reaction shown in equation 1.

$$
\mathrm{CaCO}_{3}(\mathrm{~s})+\text { energy } \rightarrow \mathrm{CaO}(\mathrm{s})
$$

\subsection{Field Emission Scanning Electron Microscopy (FESEM) with Energy Dispersive X-Ray (EDX) of SAGreM}

SEM observation shows the microstructures of the original raw materials. The SAGreM was comprised mainly of compact or hollow spheres of different sizes with a regular and smooth texture or irregularly shaped and porous (Figure 5). Generally, the figures indicate that SAGreM were stimulated by the water and that the changes occurred mostly on the edges of the particles. The pure SAGreM show amorphous structure and after reacting with water the crystalline phase was appeared in Figure 6. This appearance can be seen from flaky plate structure of calcite and the calcite flaky plate structure were transform into uniform flaky plate as shown in Figure 6. Apart from that, element of Calcium oxide were detected by using EDX as shown in Figure 6 which is higher as compared to the other elements such as silica and alumina. However, closer observation of these figures shows the presence of partially reacted or unreacted solid particles in all samples. The large amount of unreacted particles indicates a moderate degree of reaction in the system (Marjanovic et al., 2015). From this observation shows that SAGreM can be an alternative source to the calcium based material such as limestone. Early strength effect can be expected when SAGreM is paired with cement due to the calcium reaction with silica, alumina and calcium in the cement itself. 
Based on previous research, they found that SAGreM element are $\mathrm{CaO}$, gehlenite (calcium aluminate silicate) and quartz (Anuar, Ridzuan \& Ismail, 2011). The main crystalline phase of these binders was calcite $\left(\mathrm{CaCO}_{3}\right)$ and quartz $\left(\mathrm{SiO}_{2}\right)$. The similarity between the X-ray diffraction (XRD) and Electron Diffraction X-ray (EDX) patterns shows in Figure 6 below.

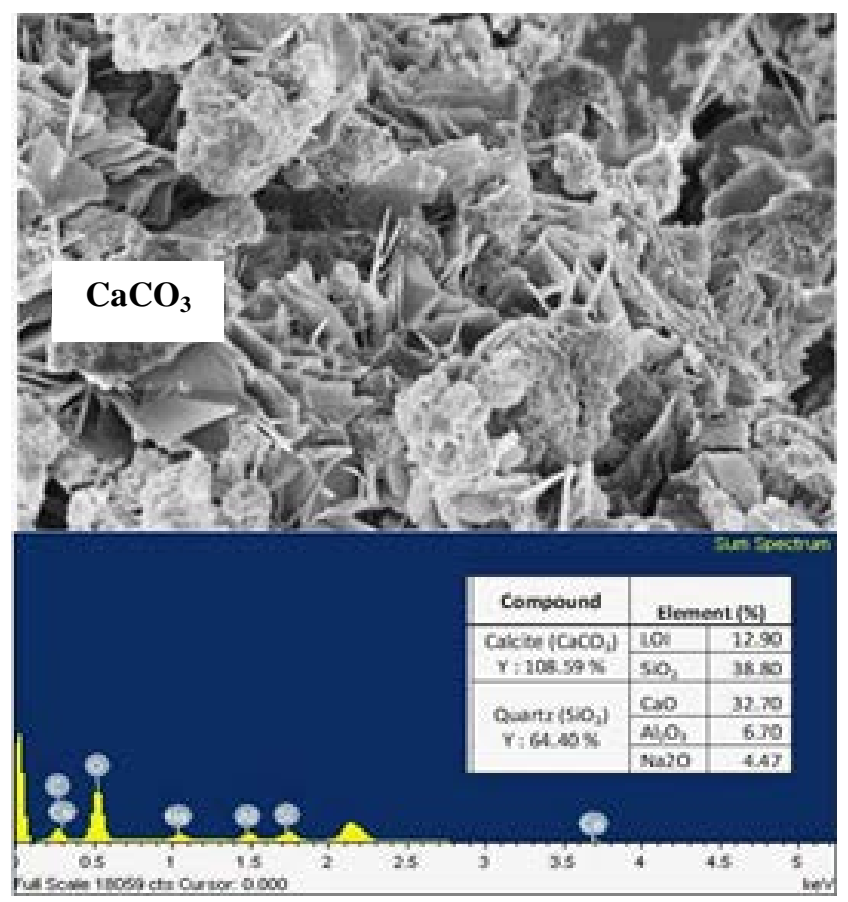

Fig. 5 - Microstructures of the SAGreM raw materials

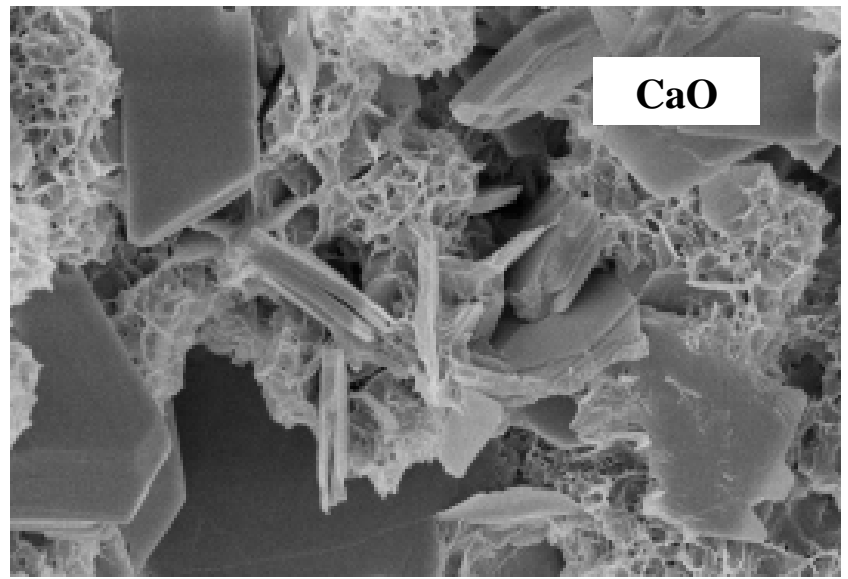

Fig. 6 - SEM and EDX analysis of raw SAGreM with water

Alternatively, calcium carbonate is prepared from calcium oxide. Water is added to produce calcium hydroxide and this reaction called exothermic because it releasing heat, as shown in Equation 2.

$$
\mathrm{CaO}+\mathrm{H}_{2} \mathrm{O} \rightarrow \mathrm{Ca}(\mathrm{OH})^{2}+\text { energy (release heat) }
$$




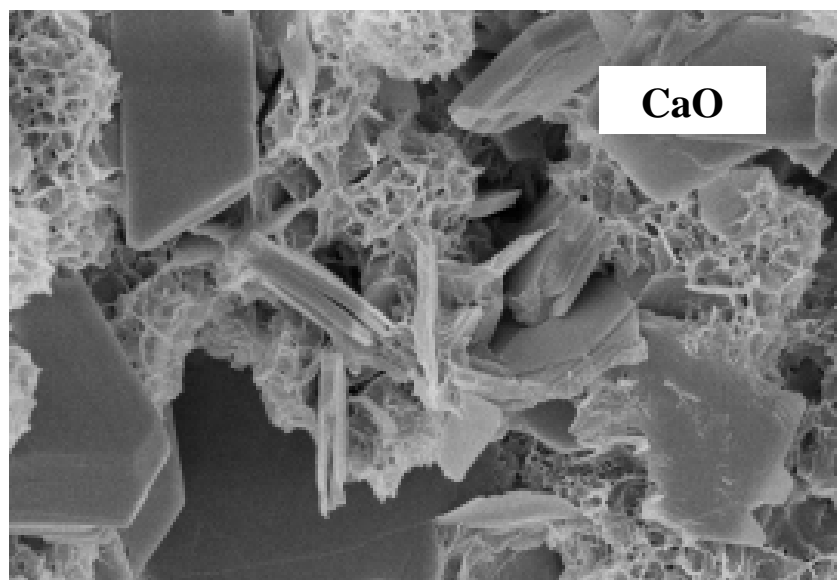

Fig.7 - SEM and EDX analysis of calcined SAGreM at $500^{\circ} \mathrm{C}$

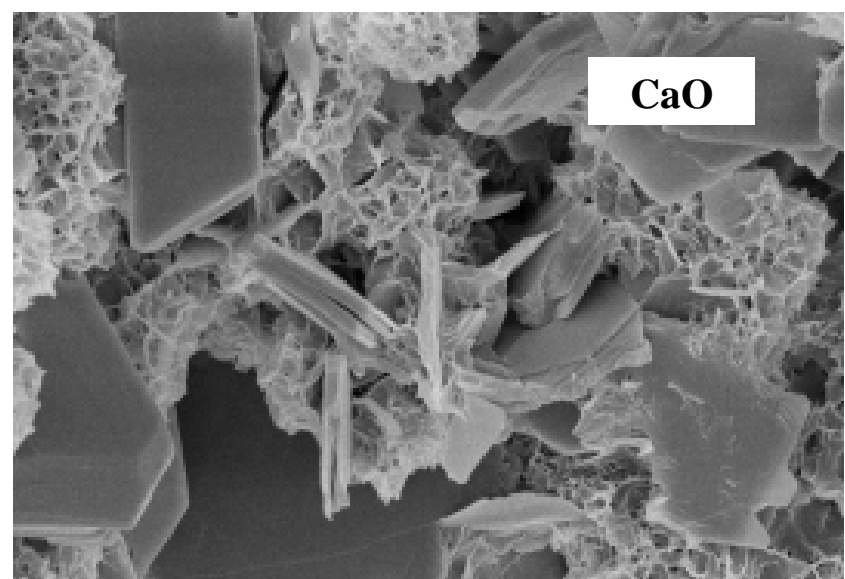

Fig. 8 - SEM and EDX analysis of calcined SAGreM at $700^{\circ} \mathrm{C}$

\subsection{Compressive Strength}

Result shows that the calcined SAGreM at $500 \mathrm{oC}\left(\mathrm{SAGreM}_{500}\right.$ + water only) gain higher strength compared to other (Figure 9). Carbon dioxide from the air reacts with the calcium hydroxide in concrete to form calcium carbonate. This reaction, called carbonatation, is a slow and continuous progression from the outer surface inward. Carbonatation increases the mechanical strength of paste.

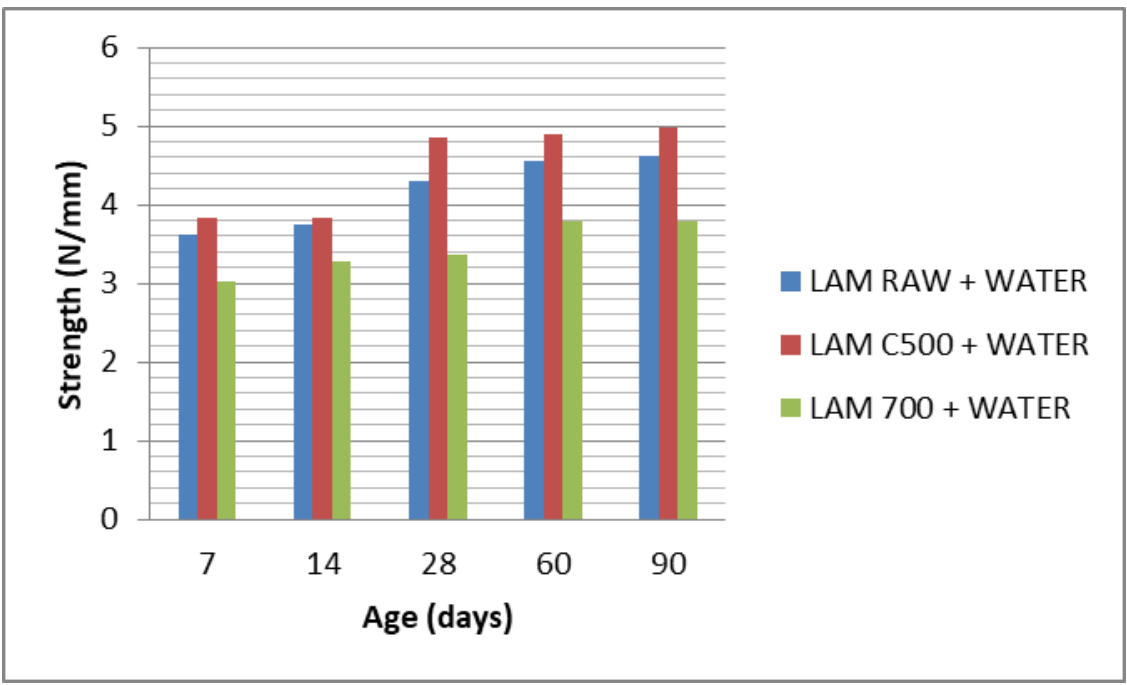

Fig. 9 - Compressive strength of SAGreM paste 
Particle size distribution (PSD) uniformity of the distribution and specific surface area has a great influence on properties of SAGreM (Celik, 2009), particularly on strength. Based on the Figure 1 in PSD result calcined SAGreM at $700 \mathrm{oC}\left(\mathrm{SAGreM}_{700}\right)$ particle size bigger compared to calcined SAGreM at $500 \mathrm{oC}\left(\mathrm{SAGreM}_{500}\right)$ and $\mathrm{SAGreM}_{500}$ show high uniformity size compared to SAGreM $M_{700}$. The optimum result is recorded by $\mathrm{SAGreM}_{500}$ as compared to the samples. This action is contributing from the flaky plate structure from the formation of calcium due to heat treatment. The unique structure performs a binding and needle-sharp action that enhanced the binding effect with cement also aggregates. Apart from that, increase in the amount of calcium also contributes to consistent effect in compressive strength as compared to the other samples.

\section{Conclusion}

Experimental works were conducted in the present study is to investigate the mineralogical composition and strength development of difference calcination temperature of LAM and the effect after activation with water. Based on result it can be concluded that:

I. Producing SAGreM using from recycling industrial waste is feasible. The use of SAGreM as a constituent ingredient in cement is not only cost effective but also facilitates the safe disposal of these solid wastes.

II. Chemical analyses found that the major crystalline phases presented in the resulted were quartz, and calcite. This was in good agreement with the compressive strength development of the SAGreM.

III. Paste sample (SAGreM500 + Water) shows the highest strength at 28 days.

\section{Acknowledgement}

The author would like to acknowledge the Research Management Institute for providing the "Fundamental Research Grant Scheme” (FRGS) (600-RMI/FRGS 5/3 (6/2015)), Institute for Infrastructure Engineering and Sustainable Management (IIESM) and Faculty of Civil Engineering, Universiti Teknologi MARA for providing the facilities to accomplish the experimental work for this research.

\section{References}

Ahmadi, B., and Al-Khaja, W. (2001). Utilization of paper waste sludge in the building construction industry. Resources, Conservation and Recycling, 32(2), 105-113.

Anon (1974). Limiting Oxygen-Index Test ASTM D 2863 - Critical Assessment of Test Procedure for Determination of Flammability of Materials. Kunststoffe, 64(3).

Anuar, K. A., Ridzuan, A. R. M., and Ismail, S. (2011). Strength characteristics of geopolymer concrete containing recycled concrete aggregate. International Journal of Civil and Environmental Engineering, 11, 59-62.

Bai, J., Chaipanich, A., Kinuthia, J. M., O’Farrell, M., Sabir, B. B., Wild, S., and Lewis, M. H. (2003). Compressive strength and hydration of wastepaper sludge ash-ground granulated blastfurnace slag blended pastes. Cement and Concrete Research, 33(8), 1189-1202.

Celik, I. B. (2009). The effects of particle size distribution and surface area upon cement strength development. Powder Technology, 188(3), 272-276.

Corinaldesi, V., Fava, G., and Ruello, M. L. (2011) Paper mill sludge ash as supplementary cementitious material. Journal of Materials in Civil Engineering, 23, 772-776.

García Giménez, R., Vigil de la Villa, R., Goñi, S., and Frías M. (2015). Fly ash and paper sludge on the evolution of ternary blended cements: mineralogy and hydrated phases. Journal of Materials in Civil Engineering, 27(9), 4014249.

Hanzic, L., and Ho, J. C. M. (2017). Multi-sized fillers to improve strength and flowability of concrete. Advances in Cement Research, 29(3), 112-124.

Journal, I., Centre, E., and Uk, D. (2015). Waste management from pulp and paper production in the European Union. Waste Management, 3(3), 32-52.

Kinuthia, J. M. (2016). Sustainability of wastepaper in construction. Sustainability of Construction Materials, 567-596.

Marjanović, N., Komljenović, M., Baščarević, Z., Nikolić, V., and Petrović, R. (2015). Physical-mechanical and microstructural properties of alkali-activated fly ash-blast furnace slag blends. Ceramic International, 41(1), 14211435.

Mozaffari, E., Kinuthia, J. M., Bai, J., and Wild, S. (2009). An investigation into the strength development of wastepaper sludge ash blended with ground granulated blastfurnace slag. Cement and Concrete Research, 39(10), 942949. 
Ridzuan A.R.M., Khairulniza, A. A., Fadzil, M. A., and Nurliza J. (2014). Effect of alkaline activators concentration to the strength and morphological properties of wastepaper-based geopolymer mortars. Material Science Forum, 803, 8892.

Segui, P., Aubert, J. E., Husson, B., and Measson, M. (2012) Characterization of wastepaper sludge ash for its valorization as a component of hydraulic binders. Applied Clay Science, 57, 79-85.

Segui, P., Aubert, J. E., Husson, B., and Measson, M. (2013). Valorization of wastepaper sludge ash as main component of hydraulic road binder. Waste and Biomass Valorization, 4(2), 297-307.

Seok Jang, H., Lim, Y. T., Kang, J. H., Young So, S., and Seok So, H. (2018). Influence of calcination and cooling conditions on pozzolanic reactivity of paper mill sludge. Construction Building Material, 166, 257-270.

Yan, S., and Sagoe-Crentsil, K. (2016) Evaluation of fly ash geopolymer mortar incorporating calcined wastepaper sludge. Journal of Sustainable Cement-Based Materials, 5(6), 370-380. 